\title{
DUYUMSAL YOKSUNLUK; ÇILECILIK VE DINSEL DENEYIM
}

\author{
Türker ALKAN
}

Tarihi inceleyen kişi, bugünü anlamayı ve yarını kestirmeyi amaçlar. Tarihsel deneyimler, bugünü ve yarını yorumlamamıza elverdikleri ölçüde anlamlıdır, önemlidir. Fakat, tarihle olan ilişkimizi tek yönlü olarak görmemek gerekir. Bugünün gelişen bilgi düzeyi ile birlikte, tarihsel olaylarn algılamamız ve yorumlamamız sürekli olarak değiştiği gibi; yarnnımıza ilişkin beklentilerimizin değişmesi de tarihi değerlendirmemize yen boyutlar getirir. Kısacası, bir taraftan tarihin yardımı ile bugünün toplumunu anlamaya ve yarını öngörmeye çalışırız; başka bir yönden de, her kuşağın bilgi ve beklentileri tarihi yeni bir 1şık altında yorumlamamıza yol açar. Dün, bugün ve yamn arasında hiç bitmeyen bir karşllıklı etkileşim söz konusudur. Konuya böyle bakınca, tarih, durağan bir olaylar yığını olmaktan çıkar, değişen toplumsal koşul ve beklentilerle birlikte yeni görünümler kazanmaya başlar.

Ekonomide, sosyolojide, siyaset biliminde, psikolojide ... ortaya atılan yeni kuram, kavram ve görüşler; tarihin kısmen ya da tümüyle yeniden gözden geçirilmesini, tarihsel olaylara yeni bir açıdan bakulmasını gerektirebilir. Psikolojide 1950'lerden bu yana üzerinde çok durulan konulardan birisi olan duyumsal yoksunluk olgusunun, çilecilik ve dinsel deneyim açısından tarihsel olaylara ışık tutup tutamıyacağı sorunlarını bu denemede irdelemeye çalışacağım.

\section{ÇILECILIK}

Din, bütün toplumlarda görülen, çok yönlü ve karmaşık olgulardan birisidir. Dini açlklamak ve anlamak için, birey ve toplum açısından bir çok varsayımlar ileri sürülmüş. Bu yazıda, çileciliğin dinsel deneyim açısından oynadığı rolü kısaca irdelemeye ve duyumsal yoksunluk çalışmalarının verileri ışığında incelemeye çalışacağım.

Çilecilik (asceticism), beden ile ruh arasında temel bir ayrım olduğunu var sayan dinlerde izlenen bir olgudur. Beden; geçici, dün- 
yevi zevk ve ihtiraslarin kaynağl olan, insanların erdeme ulaşmasını engelleyen bir öge olarak görülür. Ruh ise ebedidir, gerçek mutlulukları ve temiz zevkleri ancak onunla tadabiliriz. Bedenimizin ruhumuzu kirletmesine engel olmamiz gerekir. O halde, bedensel zevklerden vaz geçmeli, daha da önemlisi, kötülüklerin kaynağı olan bedenimize eziyet ederek ruhsal erişkinliğe ulaşmaya çalışmalıyız. Böylece, kendimizi ölümden sonraki ebedi yaşama en etkili bir biçimde hazırlamış oluruz.

Russell, çileciliğin, uygarlığın ilerlemesi ile daha çok ortaya çıktığını ileri sürüyor. Eski kutsal kitaplardan çok, yeni kutsal kitaplarda; Yunan uygarlığının ilk dönemlerinden çok, sonraki dönemlerinde görüldüğünü belirtiyor. Çileciliğin, uygar insanların hemen hepsinde, bir dereceye kadar da olsa görülebilen, kendiliğinden (spontaneous) bir olgu olduğu kanısinda. (1)

Fakat, ilkel toplumlarda, özellikle erginleme (initiation) törenlerinde, çileciliğin geniş öçüde uygulandığını görüyoruz. Bu nedenle, çileciliğin sadece uygarlıkla gelen bir olgu olduğunu ileri sürmek pek de doğru olmayacaktır. Erginleme törenine katılacak gençler, uzun süre ormanda veya dağ başlarında yalnız yaşamaya zorlanırlar. Vaftiz babaları olan yaşlı kişiden başkası ile ilişki kurmaları yasaklanır. Bu koşullar altında aylarca yaşamak zorundadırlar. Kendilerine çok az yemek verilir, bazen çok uzun bir süre oruç tutmaları istenir. Çok az uyurlar, konuşmaları yasaklanır. Gereksinmelerini el-kol hareketleri ile anlatmak zorundadirlar. Ylkanmaları, bazen hareket etmeleri bile yasaklanmıştır. Çıplak ve hareketsiz olarak toprağın üzerinde uzanıp aylarca beklerler. Bir çok erginleme töreninde, genç adama işkence uygulandiğı da görülür. Larakia kabilesinde, vaftiz babalar ve muhafizlar, hiç bir neden yokken ve birden bire, erginlenecek genci dövmeye başlarlar. Sopa ile dövülmek, altında ateş yakılan yataklarda sesini çıkarmadan yatmak, ısırılmak... bir çok kabilede görülen uygulamalardır. (2)

(1) Bertrand Russell. Why I Am Not a Christian. N.Y.: Simon and Schuster, 1957, s. 173.

(2)' Emile Durkheim. The Elementary Forms of-Religions Life. N.Y.: Collier Books, 1861, s. 349-353.

Bu arada, "beyin yıkama" adı verilen yöntemle, erginleme törenleri arasındaki büyük benzerliğe de dikkati çekmek gerekir. Her iki durumda da, bireyin kişiliğini ve dünya görüşünü değiştirme amacı vardır. Erginleme törenlerinin yakından incelenmesi. "beyin yıkama"nın hiç de sanıldığı gibi yeni ve çağdaş bir yöntem olmadığını gösterebilir. 
İsa'dan önceki Akdeniz ülkeleri, kâhinlerin, falcılarnn, keramet sahiplerinin, mucize yaratıclarınin dolup taştığı yerlerdi. Bu ortamda çilecilik hızla gelişti. Kendi bedenlerine karşı yaptıklan ezịeti çok ileri götüren çileci dindarlarin öldüğü bile oluyordu. Mısır çöllerinde yaşayan Therapentae'ler (ruhu tedavi edenler), tek başlarnna hücrelerde kalyyor ve cinsel ilişkinden kaçınıyorlardı. Örneğin, Apollonins on altı yaşında, evliliği, eti, şarabı bıraktı, hiç bir zaman traş olmadı ve beş yıl süreyle konuşmadı. Kapalı kapılardan geçmek, bütün dilleri anlamak, şeytanları kovmak, ölüleri diriltmek gibi olağanüstü yetenekleri olduğuna inanılırdı. (3) Mısır'lı ünlü din adamlanndan Hermes de sık sık ıssız yerlerde inzivaya çekilirdi. Nihayet, bir gün tek başına çölde iken Tann Oziris ile konuştu. (4)

Mısır'ın bu ortamında, çileciliği kurumsallaştıran bir örgüt biçimi olarak ilk manastırların geliştiğini görüyoruz. Korma'lı azizz Anthony ilk manastırı 300 yllarında kurdu. On beş yıl, yalnız olarak, evinin yakınındaki bir kulübede yaşadı ve çileciliği kendi köyünde yaymak istedi, fakat başarlı olamadı. (5) Bunun üzerine köyünden aynldı ve yirmi yıl çölde kaldr: Bu yalnızlığı sırasında, kendisini günaha çekmek isteyen kadın ve erkek kılığına girmiş şeytanları görüyor, onlarla baş edebilmek için durmadan dua edip oruç tutuyordu. Zamanla, Anthony'nin çevresinde kendisi gibi yaşayan kişiler toplanmaya başladı. 315-320 yllarında, bu münzeviler topluluğunu Pachamins örgütleyerek manastırlarn geliştirdi (manastır, yalnız yaşayan anlamina geliyordu). Bu manastırlar öyle bir ilgi topladı ki, kısa bir süre sonra 10.000 rahib ve 20.000 rahibe buralarda yaşamaya başladı. (6)

Manastırlar, bir arada yaşanlan, küçük hücrelerde inzivaya çekilinen yerlerdi. Mimari ve yaşama biçimi, dışarı ile olan ilişkiyi en az düzeye indirecek tarzdayd. Bununla birlikte, manastırların çevresinde yaşayan, çok ender durumlarda manastırlara gelen ge-

(3) Will Durant, Caesar and Christ. N.Y.: Simon and Schuster, 1844, s. 525-526.

(4) Enver Behnan Sapolyo. Peygamberler Tarihi. Ankara: Onasya Yayınlan, 1888, 6. 31-32.

(5) Isa ve Muhammed'in de ilk sıkışlarmana kendi kentlerinde başarısız olmalan ilginçtir. Belli ki kişinin kendi köyünde peygamber olması oldukça zor bir iş.

(8) Bertrand Russell. A History of Western Philosophy. N.Y.: Simon and Schuster, 1845 , s. 376.

John B. Noss. Man's Religions. N.Y.: Macmillan, 1868, s. 841-642.

Encylopedia of Religion and Ethics. (Ed.) J. Hastings. N.Y.: Charles Scribner's Sons, 1951, C. VII, 6. 788 . 
niş bir münzevi topluluğu da bulunuyordu. Bu münzeviler, mağaralarda, çöllerde, direklerin ve ağaçların tepelerinde, kovuklarda yaşıyorlardı. Bu koşullarda uzun yıllar geçirenler vardı. Kuşkusuz ki, yalnız geçen sürenin uzunluğu ile birlikte, kutsallıklam da artıyordu. Manastırda uyulması zorunlu kuralların başında sessizlik ve yalnızlık geliyordu. Manastırlarda oturanların dı̧ dünya ile iletişim kưrması çok katı kurallarla sınırlandırılmıştı. Dağlarda ve çöllerde yalnız yaşayan münzevilerin yalnızhğını bozan tek şey, ara sura yemek getiren ruhani babaları idi. Bu durumda da konuşulmaz, yiyecek belirli bir yere burakılır ve gidilirdi. Misır'da gelişen bu manastırlar, Suriye'de ve Anadolu'da hızl yayıldı, daha sonra Avrupa'da görülmeye başlandr. (7)

Hırıstiyan azizelerinin büyük bir çoğunluğu, "sessizlik ve yalnızlık"la eğitildiler. Aziz Benedict, yirmi yaşında, Roma'daki zengin ve rahat yaşamını bırakıp bir mağaraya kapandı ve üç yıl süreyle kimseyle görüşmeden orada kald. Aziz Bernard, otuz sekiz yıl, saman yatağından başka hiç bir şeyin sığmadığı küçük bir hücrede yaşadı. Kilisenin verdiği görevleri yerine getirmek için, bu süre içinde sadece on iki kez hücresinden çıtı. Aziz Francis, derin bir vadideki kulübesinde yalnız oturuyor, oruç tutuyor, bir takım dinsel imgeler görüyordu. Uzun bir oruç ve dua sonucunda, yalnız havada uçan İsa'yı görmekle kalmadı, İsa'nın çarmıhtaki yara izlerinin kendi vücudunda da belirdiğini izledi. Aziz Finnchua, koltuk altlarından geçirilmiş demirlerle kendisini boşlukta sallandırarak yedi yıl geçirdi. Böylece, dünyada boşalttığı yer karşıllğında, kendisine cennette bir yerin ayrılmasını garanti etmek istiyordu. Aziz Mochua, kendi isteği ile bir hapishane hücresinde yaşıyordu. Aziz Kevin, yedi yll ayakta, uyumadan ve kımıldamadan durdu. Bu arada açı duran avucunun içine kuşların yuva yapıp yumurtalarını bıraktığı ve yavrulannı yetiş- tirdiği söylenir. (8)

İsa'nın üzerinde büyük etkisi olan ve onu taktis eden Yahya, halkın arasına karışıp dinsel bildirisini iletmeden önce uzun yıllar çöllerde yalnız yaşadı. İsa da takdis olmasını izleyen kırk gün içinde çöllere çekildi, yalnız kaldı. Bụ sırada Şeytan'ın İsa'yı baştan çıkarmak için çok uğraştığı söylenir. (9)

(7) Noss, s. 642.

Encyclopedia of Religion and Ethics, c. VII, VIII, s. 784-788.

(8) Will Durant. The Age of Faith. Simon and Schuster, 1950, s. 791-800.

Bertrand Russell. A History of Western Philosophy, s. 377-380.

Encyclopedia of Religion and Ethics, c. VII, VIII, s. 72 ,

(9) Noss, S, 596 . 
Hindu ve Buda dinlerinde de rahipler manastırlarda, kavalara oyulmus inlerde, ormanlarda uzun süre yalnız yaşayarak meditasyona dalarlardı. Benares'li bir Brahman fakiri, çivili yatağı üzerinde çıplak olarak otuz beş yıl uzanmıştı. Tirnaklarn avuçların delip diğer taraftan çlkuncaya kadar ellerini yumruk yapıp oturanlar da vardır. Yıllarca konuşmayanlar, uzun süreler oruç tutanlar çok sık görülürdü. Bir Hindu dul kađin yer altında yaptırdığı hücresinden çıkmadan 38 yll geçirmişti. Büyük bir üne kavuştu, ülkenin uzak köşelerinden kendisini ziyarete gelenler oldu. (10)

Buda'nun kendisi de bu deneyimlerden geçti. Yirmi dokuz yaşında zengin babasının evini terk ederek ormanlara daldı. Altı yı́ süreyle tek başına ormanlarda ve dağlarda dolaştı. Çok az yiyerek ve bedenine eziyette bulunarak çileciliği denedi. Rahatsız edici elbiseler giyiyor, günlerce aymı pozisyonda duruyor, dikenler üzerinde oturuyor, çürüyen cesetler arasında yaşıyor, yıkanmıyordu. Kir, bedeninden kendiliğinden dökülür olmuştu. Günde bir tahıl veya pirinç tanesiyle idare ettiği gibi, bazen kendi pisliğini bile yediği oluyordu. Nihayet, "büyük gerçek" kendisine açıklanıncaya kadar kalkmama kararı ile bir incir ağacinın altına oturdu. Sekizinci gün büyük deneyim başladı ve kırk dokuz gün süreyle aynı yerde kald. (11)

Janiizmin kurucusu Mahavira da Buda'nınkine benzer bir yaşam sürdü. Bir mihracenin oğlu idi. Servetini bırakarak otuz bir yaşında din adamlığına, çileciliğe başladı. Elbiselerini çıkarıp çınl çıplak dolaşarak tanrısal gerçeği aramaya koyuldu. Üzerine biriken böcekleri ve sinekleri kovmuyor, kendisini kaşımıyordu bile. Konusmama yemini olduğu için, kendisine kızan halkın, meditasyonu sırasında işkence yapmasına, bıcakla vücudunu kesip, saçlarını yolmasına aldırmadan sessizce duruyordu. Böylece geçirdiği on üçün'cü yılın sonunda tanrısal gerçeği buldu, Nirvana'ya ulaştı. (12)

Konuşmama, yememe, toplumsal yalitlanma gibi olguları, eski Japon dini olan Şinto'da da görüyoruz.(13)

Müslümanlıkta yaygın bir çilecilik uygulaması olmamakla birlikte, bir çeşit sufì manastırı olan hanegâhlarda, yalnızlık, sessizlik,

(10) Encyclopedia of Religion and Ethics, c. I, s. 82-95; c. VII, VIII, s. 782-797.

(11) Noss, s. 172.

Huston Smith. The Religions of Man. N.Y.: Harper and Row, 1965, 8. 93-96.

(12) Noss, s. 156-162.

(13) Encylopedia of Religion and Ethics, c. I, s. 96. 
oruç ve uykusuzluk, şeytana karşı mücadele ve olgunlaşmada belli başlı araçlar olarak kullanılmıştı. (14)

Buraya kadar, sessizlik ve yalnzzlığın, dinsel deneyimde, özellikle, "vahiy", "nirvana", "melekleri görme", "şeytanla mücadele etme", "tanrisal mesajlar alma" konularında büyük bir önemi. olduğunu gördük. Kendilerini toplumdan yalitlayarak meditasyona dalan bu kişiler, gerçekten doğaüstü, tannsal bir deneyim mi geçiriyorlardı, yoksa, içinde bulundukları fiziksel-biyolojik koşullamn dogal bir sonucu olarak bazı imgeler görüp sesler işitiyor ve bunları beklentileri doğrultusunda $\mathrm{ml}$ yorumluyorlardı? Bu konuda aydınlatıcı olabilecek bir dizi çalışma yapılmış bulunmaktadır. "Duyumsal yoksunluk" başlı̆ı altında toplanabilecek olan bu çalışmalara şimdi kısaca bir göz atalım.

\section{DUYUMSAL YOKSUNLUK}

Duyumsal yoksunluk çalışmaları, uzun süre hastahanede yalıtlanmış hastalarda gelişen psikopatolojik bazı belirtilere dikkati çèken Solomon ve arkadaşlarının 1958'de düzenledikleri bir sempozyum ile başladı. Bu hastalarda veya çok yüksekte, uzun süre yalnız uçan pilotlarda, patalojik endişe duygusu, sabuklama (hezeyan : delusion) ve sanrilar (hallucinations) görüldü. Bu belirtiler, tıbbî veya psikiyatrik tedavi yöntemleri ile değil, çevrede algılanan ortamı zenginleştirerek giderilebildi.

Bunun üzerine, duyumsal ve algisal yoksunluk çalışmalan başla$d_{1}$ ve giderek psikolojinin önemli çalışma alanlarından birisi durumuna geldi. Duyumsal yoksunluk çalışmalarında, uyaranların en düşük olası düzeye indirilmesi amaçlanır. Deneklerin, özel olarak yapılmış havuzlarda uzun süre su altında tutulması, ses geçirmeyen karanlık odalarda hareketsiz olarak yatırlması gibi yöntemler uygulanır. Algısal yoksunluk çalışmalarında ise, amą, uyaranları en düşük düzeye indirmek değil, uyaranlarnn anlamlı ve örgütlü bir bütünlük içinde algılanmasına engel olmaktır. Yaratılan yapay ortamda (genellikle laboratuar odası), işlk ve ses uyaranlan, geleneksel algılama alışkanlıklarının dışına taşan düzensizlik, örgütsüzlük ve rastgelelikle verilir.

(14) A.J. Arberry, Sufism. London: George Allen and Unwin Ltd., 1950, s. 75. Encyclopedia of Religion and Ethics, c. I, s. 104.

(15) Bu sempozyumda sunulan bildiriler daha sonra yayinlandi: P. Solomon, P.E. Kubzansky, P.H. Leiderman, J. H. Mendelson, R. Trumbull, D. Wexler. Sensory Deprivation. Cambridge, Mass.: Harvard U.P., 1981. 
DY (duyumsa yoksunluk) çalışmaları sırasında, beyin dalgalannın faaliyetinin azaldığı ve telkin (propaganda) yoluyla davranış değişikliğinin oldukça kolay bir biçimde gerçekleştirildiği izlendi. Fakat, her iki durumda da denekler arasında büyük farklar bulunduğu görüldü. (16) "Beyin yıkama" adı verilen davranış değiştirme yönteminde bireylerin katı bir biçimde çevrelerinden yalıtlanmasının nedeni, bu gözlemlerle daha iyi anlaşılmaktadır.

Yapılan çalışmaların bir kısmında, yalıtlanmayı izleyen dönernde, dikkati bir noktada yoğunlaştırma ve problem çözme yeteneklerinin bir ölçüde azaldığı görüldü. Öznel olarak bilişsel yeteneklerin azaldığına ilişkin bu tür raporlar varsa da, yapılan nesnel ölçümlerde bu durumun gerçekte pek de önemli olmadiğı anlaşıldı. Yapılan başka çalışmalarda ise, bilişsel-düşünsel yeteneklerin hiç bir biçimde sekteye uğramadiğı, hatta yalıtlanmayı izleyen ilk günler içinde, ezberleme, sözlü ve soyut uslamlama (muhakeme) gibi yeteneklerde ilerleme olduğu bile saptandı. DY'un uzaması durumunda, uğranılan bilişsel zedelenmelerin uyumla düzeldiği de görüldü. $\mathrm{Bu}$ arada, DY sirasında öğrenme yeteneğinin önemli ölçüde arttığı izleniyor. Yapılan çalışmalarda, bilişsel-düşünsel düzeyde bir zedelenme doğması durumunun, duyumsal yoksunluktan çok algisal yoksunlukla ilgili olduğu bulundu. Özet olarak, DY sonucunda, bireyin bilişsel-düşünsel yeteneklerinden genel bir sorun ortaya çıkmamaktadır. Bu yeteneklerin bir kısmı kısa bir süre zedelense bile, uyumla tekrar eski düzeyini bulmaktadır. Öte yandan, çilecilik ve dinsel deneyim açısından önemle üzerinde durulması gereken bir nokta, sözlü ve soyut uslamlama yeteneklerinde belirli bir gelişmenin görülebilmesidir. (17)

DY deneylerinde, deneklerin bir kısmında sanrısal imgeler ve ses işitmeler olduğu görüldü. Bu imge ve sesler çoğu kez basit bir yapı göstermekle birlikte, bazı durumlarda yüksek derecede karmaşık ve örgütlüdür. (18) Freedman ve arkadaşlarının yaptığı araştır-

(18) Duane P. Schultz. Sensory Restriction: Effects on Behavior. N.Y., Academic Press, 1865, s. 57, 72-76, 80.

(17) Schultz, agy, s. 61-72, 76-77.

J.P. Zubek, W. Sansom, A. Prysiaznink, "Intellectual Changes During Prolonged Perceptual Isolation," Canadian Journal of Psychology, 1860, 14, s. 233-243.

(18) N. Cohen, "Sources of Reports of Visual and Auditory Sensations in Perceptual Isolation Experiments." Psychological Bulletin, 1964, c. 62, s." 1-20. J.P. Zubek, "Effects of Prolonged Sensory and Perceptual Deprivation." British Medical Bulletin. 1864, c. 20, s, 38-42. 
mada, sekiz denek, sekiz saat süre ile DY deneyinden geçti. Deneklerin bir kusmı mızganma (hypnagogic) durumuna geçti, bir tanesinde açıkça paranoid eğilimier belirdi. Deneklerin dördünde vücut imgeleri değişti (organlann vücutlarından ayrıldığını görme gibi), diğerleri ise paranoid nitelikte korkular duydular. (19) Bir başka deneyde de, 2-3 gün süreyle DY deneyinden geçen 29 denekten 25'inin sanriya ilişkin raporlar verdiği görüldü. (20)

Sanr görme üzerine telkin ve beklentilerin etkili olup olmadığın saptamak için yapılan bir diğer çalışmada, 14 erkek denek sadece bir saat DY deneyinden geçirildi. Fakat, deneyden önce, beklenen sonuçlarla ilgili olarak (algllanacak sannsal ses ve imgeler üzerine) bilgi verildi ve "sanr yaratıcl" (hallucinogenic) olduğu söylenen (aslında hiç bir etkisi bulunmayan) birer hap verildi. Bu koşullar altında, uzun süre DY deneyiminden geçmiş olan deneklerin bildirdiğinden çok daha yüksek oranda sannısal imge ve ses alg1landığına tanık olundu. Deneklerden on ikisi imge, on dördü de ses algıladıklannı bildirdiler. (21) Fakàt, daha sonra yapılan çalışmalar, Jackson ve Kelly'nin bulgularını doğrulamadı. Telkin ve beklentilerin, basit ve örgütlenmemiş sanrısal algnlamalarda etkili olduğu, daha üst düzeydeki sanrısal algılamalan etkilemediği görüldü. (22)

Açıklanması zor bir olgu, Solomon ve arkadaşlarının, DY sırasunda izlenen sanrisal deneyimlere dikkati çekmesinden donra yapılan ilk araştırmalarda yüksek oranlarda sanrısal alglamalar olduğunun bildirilmesine karşın, son yllarda yapilan deneylerde sanrssal algılama bildirimlerinin gittikçe düşmekte olmasıdır. Genellikle, yapılan araştırmalarda, sanrisal imge algılanması deneklerin yarısında görülmekte, daha örgütlü imgelerin alglanmasma ise deneklerin sadece \% 20'sinde rastlanmaktadir. (23)

Sanrisal algilama, bir uyku öncesi veya kendinden geçme durumunda belirmiyor. Tam tersine, belirli derecede bir uyanıklığı ve

(19) S.J. Freedman, H.U. Grunebaum, M. Greenblatt, "Perceptual and Cognitive Changes in Sensory Deprivation,' Sensory Deprivation. (Der. Solomon), s. 58-71.

(20) H. Woodburn, "Cognitive and Psychological Effects of Perceptual Isolation,"

Sensory Deprivation, (Der. Solomon), s. 6-33.

(21) C.W. Jackson ve E.L. Kelly. "Influence of Suggestion and Subjects' Prior Knowledge in Research on Sensory Deprivation," Science, 1962, c. 132, s. 211-212.

(22) Marvin Zuckermann, "Hallucinations, Reported Sensations, and Images," Sensory Deprivation: Fifteen Years of Research. N.Y.: Meredith Co., 1989, 8. $109-111$.

(23) Zuckermann, 8. 88. 
uyarılmışlığı gerektiriyor. $\mathrm{Bu}$ olgu, deneklerin bildirimlerinden ve beyin dalgası ölçümlerinden çıkanlıyor. Zaman içinde, önce belirli bir anlam taşımayan örgütsüz sanrısal algılamalar ortaya çıkıyor, sonra, daha anlaml, karmaşık ve üst düzeyde örgütlènmiş algılamalar izleniyor. Yapılan çalışmalarda, kişilik farklarının ve zekânın sanrısal deneyimleri etkileyip etkilemediği konusunda kesin bir sonuca ulaşlamadı. (24)

Yapay laboratuar koşulları dışında, doğal nedenlerle uzun süre yalnız kalan kişilerle ilgili araştırmalarda da, yukarnda özetlenen deney sonuçlarına benzer algılama ve davranma biçimlerinin geliştiği görüldü. Bu kişilerde, özellikle, sanrısal imge ve ses algılamaları, kendini "kurtancl" gibi görme eğilimi, doğaüstü güçlere inanç, yaşayan varlıklara karşı büyük bir sevgi, cansız cisimlerle konuşma ... gibi davranış, tutum ve eğilimler ortaya çıkıyor. Fakat, yalnızlığın bu etkilerinin, insanlar veya gruplar üzerinde aynı biçimde kendisini göstermediği de izleniyor. (25)

(24) Zuckermann, s. 105, 119-121.

(25) J. Lilly, "Mental Effects of Reduction of Ordinary Levels Physical Stimuli on Intact Healthy Persons, Psychiat. Res. Rep., 1958, c. 5, s, 1-9. 


\section{SONUÇ}

Çilecilik deneyimlerinin dinle ilişkisini kısaca gördükten ve DY çalışmalarının sonuçlarını gözden geçirdikten sonra; "yalnız kalma", "sessizlik" gibi durumlarn, "vahiy", "nirvana", "melekleri görme", "Tanrı ile konuşma" deneyimlerine yol açtığını ileri sürebiliniz. Çilecilerin baş vurduğu, uzun süre oruç tutma, kenḍi bedenine eziyet etme gibi davranışlar, büyük bir olasılıkla, sanrısal imge görme sürecini hızlandıran, sanriları daha canlı ve örgütlü kılan araçlardı. Bunların yanısıra, geçireceği dinsel deneyimin niteliği konusunda kendisini önceden koşullandırmış olan kişinin beklentileri de sonu$\mathrm{cu}$ etkiliyor olabilir.

Ayrıca, duyumsal yoksunluğu doğal olarak sağlayan Ortadoğu'nun tekdüze görünümlü çöllerinin, bu bölgede çok sayıda peygamber ve din çlkmasını etkileyen ögelerden birisi olduğu da söylenebilir.

$\mathrm{Bu}$ söylenenler, kuşkusuz ki, din olgusunu çileciliğin mekanik bir yorumuna bağlamak anlamına gelmeyeceği gibi; meditasyonun tek sonucunun "tanrısal deneyim" olduğu savı da ileri sürülmemektedir. Çilecilik ve meditasyon, belirli dozlarda kullanıldığı zaman, gerçekten insanın kişiliğini zenginleştiren, iç dünyamızı anlamamı$\mathrm{zl}$ ve kendimizi tanımamızı sağlayạ, irademizi bileyen bir yöntem olabilir. Fakat, bu yöntemi, yukaridaki örneklerde görüldüğü gibi aşırı bir biçimde kullanmak, bedensel sağlığı zedeleyebileceği gibi, akıl sağlığı açısından da pek iyi olmayan sonuçlar doğurabilir. 